\title{
TYMPANOPLASTY TYPE-1: DIFFERENT APPROACHES AND THEIR SURGICAL OUTCOMES
}

\author{
Fazal-I-Wahid, Abdul Manan*, Muhammad Saleem**, Bakht Zada, Habib-Ur-Rehman, Naseem Ul Haq, Muhammad Javaid \\ Teaching Institute, Lady Reading Hospital, Peshawar Pakistan, *Bolan Medical College, Quetta Pakistan, \\ **KMU Institute of Medical and Dental Sciences, Kohat Pakistan
}

\begin{abstract}
Objective: To calculate the surgical outcomes of different approaches of tympanoplasty type 1 in terms of air bone gap closure, wound healing, and postoperative pain.

Study Design: Prospective cross-sectional study.

Place and Duration of Study: Department of ENT, Head and Neck Surgery, Medical Teaching Institute (MTI), Lady Reading Hospital (LRH), Peshawar, Pakistan from Jun 2018 to May 2020.

Methodology: Size of sample was 75 patients divided into three groups. Consent was obtained from all the patients included in study. After proper evaluation and relevant investigation pre- and post-operative PTA was performed. Tympanoplasty type-1 was performed by the same surgeon by the three approaches following established otological surgical protocol. Collected data was entered in SPSS-25 for analysis.

Results: All 75 patients were divided into three equal groups. Male were 55 (73.3\%), females were 20 (26.7\%). Male: female ratio was 2.7:1. Majority of patients presented in $2^{\text {nd }}$ and $3^{\text {rd }}$ decades of life $31(41.33 \%)$ and $28(37.33 \%)$ respectively. Preoperative mean $\pm \mathrm{SD}$, ABG in groups $\mathrm{A}, \mathrm{B}$ and $\mathrm{C}$ were $37.60 \pm 11.28 \mathrm{~dB}, 37 \pm 9.68 \mathrm{~dB}$ and $31.80 \pm 12.40 \mathrm{~dB}$, respectively. No significant difference was found amongst the three groups regarding pre-operative and post-operative ABG $(p=0.85$ and $p=0.4)$, respectively. Mean $\pm \mathrm{SD}$, wound healing time in Groups A, B and C were $1.00 \pm 0.00,1.80 \pm 0.40$ and $1.76 \pm 0.43$ respectively with $p=0.0001$ and similarly postoperative pain with $p=0.001$. The wound healing time and post-operative was statistically better $(p<0.05)$ in group A (Transmeatal approach) than other groups.

Conclusion: Although wound healing time and post-operative pain were significantly minimum in transmeatal approach for tympanoplasty, but overall success rate of tympanoplasty was not statistically significant among these three approaches.
\end{abstract}

Keywords: Tympanic membrane, Perforation, Surgical outcome, Tympanoplasty.

How to Cite This Article: Wahid F, Manan A, Saleem M, Zada B, Rehman HU, Haq NU, Javaid M. Tympanoplasty Type-1: Different Approaches and Their Surgical Outcomes. Pak Armed Forces Med J 2021; 71(Suppl-3): S495-499. D Doi: https://doi.org/10.51253/pafmj.v1i1.7938

This is an Open Access article distributed under the terms of the Creative Commons Attribution License (https://creativecommons.org/licenses/by-nc/4.0/), which permits unrestricted use, distribution, and reproduction in any medium, provided the original work is properly cited.

\section{INTRODUCTION}

Chronic Suppurative Otitis Media (CSOM) is a common otological problem encountered by otolaryngologist worldwide. Its prevalence in developing courtiers is $2-17 \%$. The risk factor for CSOM includes poor hygiene, overcrowded families, persistent middle ear infection and underlying sino-nasal pathologies. ${ }^{1}$ Clinical presentations of CSOM include aural discharge, decreased hearing and pain in ears. CSOM can be treated medically with appropriate medications and ensuring proper hygiene. In case acuteotitis media is not addressed properly it may convert into CSOM, where it can be treated surgically. ${ }^{2}$ Ear drum perforation can be closed surgically called myringoplasty if themiddle ear is also explored with, it is called tympanoplasty. Different materials are used for closure of the tympanic membrane defect. Historically, myringoplasty was started by Berthod in 1878 using thick skin graft. Wullstein and Zollner also studied split skin graft. The

Correspondence: Dr Fazal-I-Wahid, Department of ENT, Medical Teaching Institute, Lady Reading Hospital, Peshawar Pakistan commonly used grafting materials include the temporalis fascia, tragal and Conchal cartilage and vein grafts. ${ }^{2,3}$ Various approaches are used for repair of TM. The commonest approaches are transmeatal, endaural, post-aural and endoscopic. The feasibility of these approaches depends on site, size of TM perforation, width and anatomical orientation of the external auditory canal and surgeon preference. Trans-meatal approach is somewhat minimally invasive technique that can be used where meatus is wider and TM perforation is small. ${ }^{4}$ In case of posteriorly located TM perforation end-aural approach can be used with limited incision of canal wall. However, post-aural incision is commonly used for anteriorly located or large TM perforation. Each of these approaches encompasses advantages and disadvantages. Any surgical procedure performed for repair of TM perforation can be accompanied by complications. These complications may affect both short and long terms results of myringoplasty and tympanoplasty. Some of the complications include infection, tinnitus, dizziness, failure to take graft, and sensorineural hearing loss. ${ }^{1,3,5}$ 
This study aims to determine surgical outcome of tympanoplasty type 1 in terms of acoustic improvement, wound healing, postoperative pain and graft success. This study is never conducted in this institute before, so it may help devise a protocol for repair of TM perforation in the future, focusing on a shorter duration of surgery and maximum success of the procedure.

\section{METHODOLOGY}

This prospective cross-sectional study was carried outat the Department of ENT, Head and Neck Surgery, Medical Teaching Institute (MTI), Lady Reading Hospital (LRH), Peshawar, Pakistan from June 2018-May 2020. A sample of 75 was computed by G-Power calculator taking a 0.05 and $\beta 0.05$. These patients were divided into three groups according to approach to the middle ear with anequal number of 25 patients in each group. In group A Transmeatal approach was performed, in group B end-aural while in group C post-aural approach was adopted. Non-probability (Convenient) sampling method was used. Informed consent was obtained from all the participants of the study.

Inclusion Criteria: Male and female patients aged from 15-50 years, with dry tubotympanic type otitis media, having conductive type hearing impairment with Air-Bone Gap not more than $20 \mathrm{~dB}$ were included.

Exclusion Criteria: Patients with active or attico-antral type and not willing for study were excluded.

After admission each patient was properly assessed by taking history and examination. Relevant investigations were performed. Autoscopic examination was performed and TM perforation was established. Pre-operative and post-operative pure tone audiometry (PTA) was performed by the senior most audiologist. The PTA machine used was Amplaid 455 made in Italy. Frequencies checked in PTA were 500, 1000, 2000 and $4000 \mathrm{kHz}$. Air bone gap on PTA was computed before and after surgery. Success of the surgery was denoted by reduction in post-operative air bone gap and closure of the TM defect. Post-operative pain and wound healing was calculated for all the three groups. Graft materials used were temporalis fascia and tragal cartilage. Every patient was called for follow up to look for post-operative pain, wound healing, graft success and ABG closure.

Data were collected on well-designed proforma. These data were entered into SPSS-25 and analyzed. For qualitative data frequency and parentage was calculated while for quantitative data Mean \pm SD were calculated. Confidence interval was $95 \%$ and $p<0.05$ was taken significant.

\section{Procedure}

Tympanoplasty type 1 was performed by author himself, keeping in view universally accepted protocol for ear surgery. After intubation with general anesthesia of the patient in supine position, local anesthesia with local anesthetic of $2 \%$ xylocaine mixed in 1: 80000 epinephrines was injected into the meatus in all four quadrants and in tragus. The area of interested was properly scrubbed with pyodine solution and then draped.

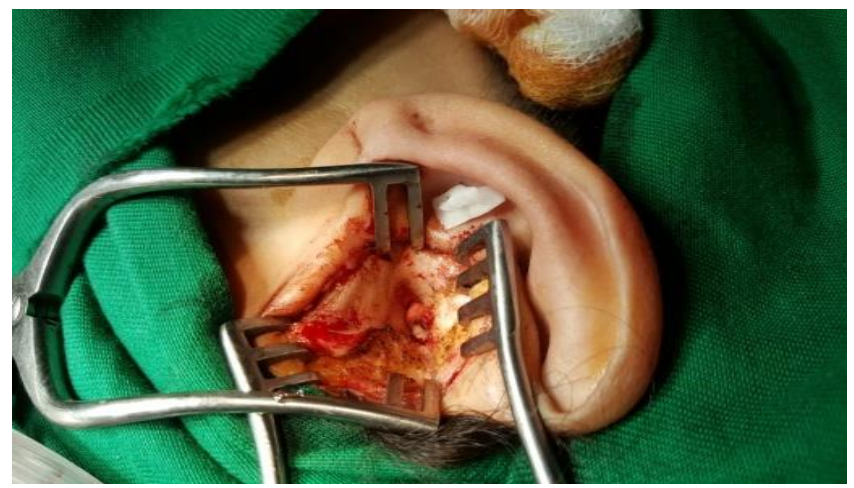

Figure-1: Endaural approach for right ear tympanoplasty type 1.

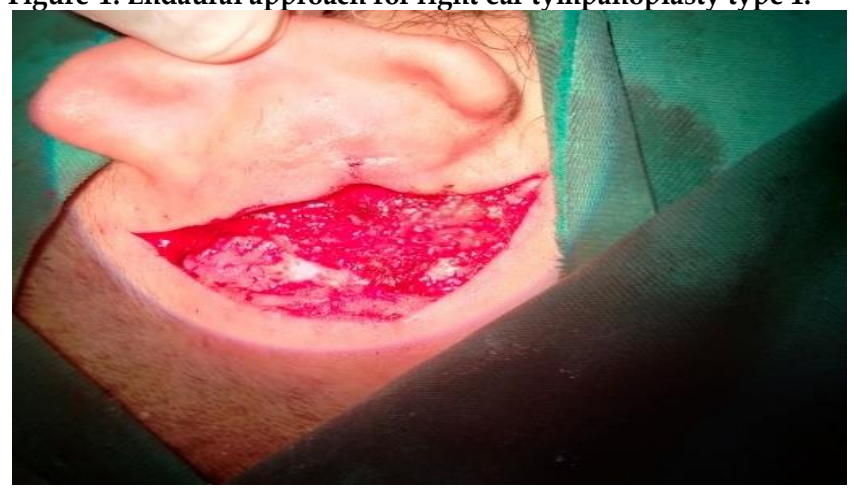

Figure-2: Postaural approach for right ear tympanoplasty type 1.

Then tragal cartilage graft was taken incising skin with size 15 surgical blade, and then cartilage was thinned out and shaped according to need of TM perforation. Temporalis fascia graft was taken from superior part of the post aural incision. After selecting any of the three approaches, middle ear was assessed for any pathology. Then margins of the perforation were freshened, tympanomeatal flap was properly elevated. Few pieces of gelfoam were put in middle ear, then tragal cartilage reinforced with temporalis fascia graft was used and finally tympanomeatal flap was repositioned in appropriate manner. Then put gelfoampieces again in meatus and it was packed with polyfax pack and wound was closed and bandage applied. Patient 
recovered from anesthesia and shifted to ward for post -operative care. Patients were put on antibiotics, analgesics antihistaminic and vasoconstrictor nasal spray to keep eustachian tube patent. Patients were instructed to avoid straining, forceful nasal blowing and coughing. Every patient wascalled for follow up visit. On followup visitautoscopy, endoscopy and PTA were performed and findings were noted.

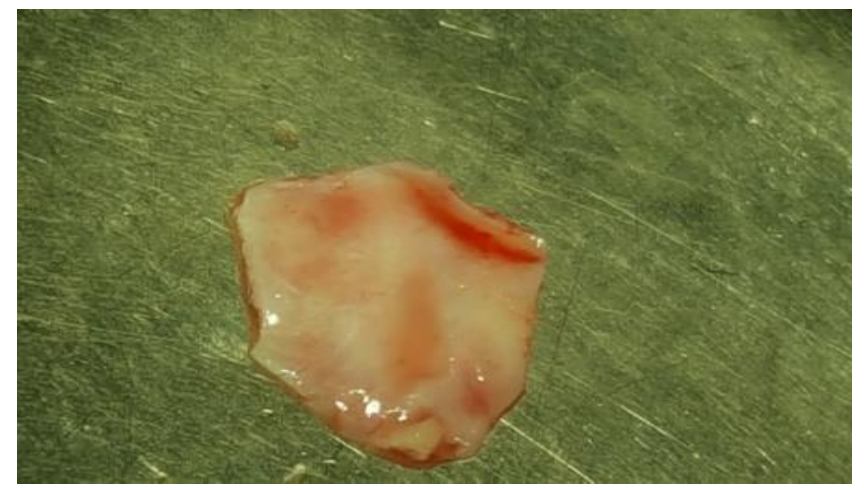

Figure-3: Tragal cartilage graft harvested.

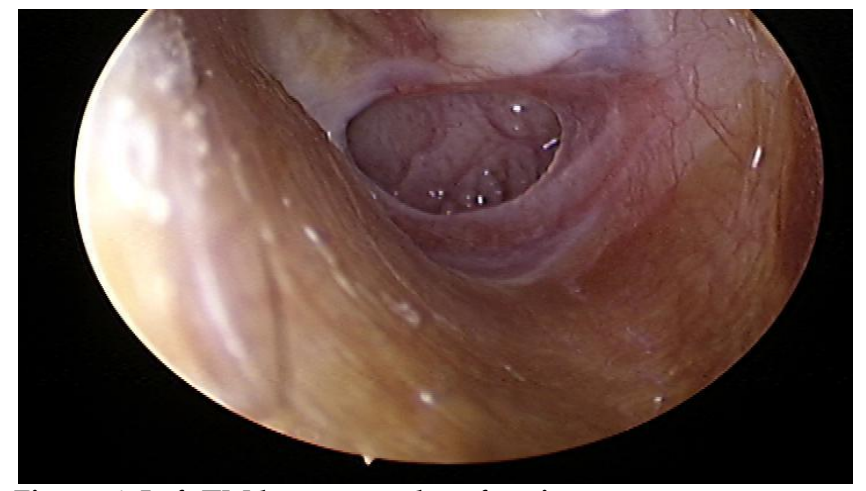

Figure-4: Left TM large central perforation.

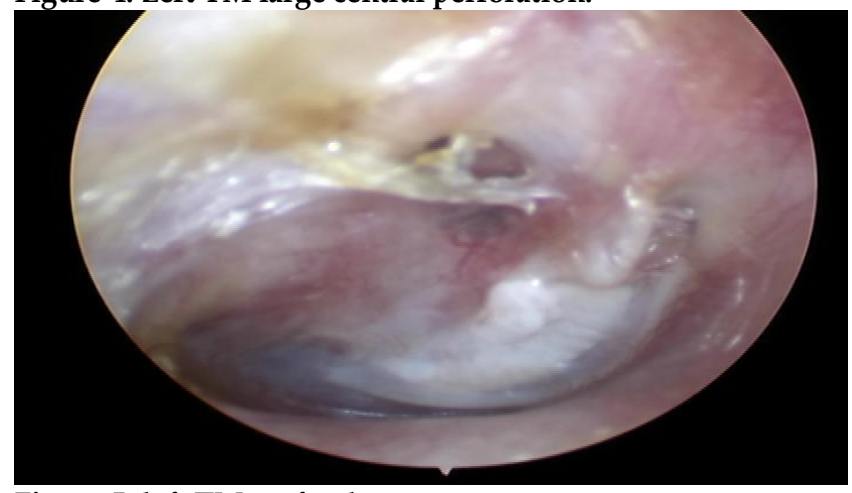

Figure-5: left TM graft taken.

\section{RESULTS}

All patients included counted 75, who were divided into three equal groups. Male were 55 (73.3\%), females were $20(26.7 \%)$. Male: female ratio was 2.7:1. Majority of patients presented in $2^{\text {nd }}$ and $3^{\text {rd }}$ decades of life $31(41.33 \%)$ and $28(37.33 \%)$, respectively. There were $22(29.33 \%)$ males and $9(12 \%)$ females in age group 16-25 years, while in age group 26-35 years males were 20 (6.67) and females were 8 (10.67\%) (Table-I). Pre-operative mean $\pm S D, A B G$ in groups $A, B$ and $C$ were $37.60 \pm 11.28 \mathrm{~dB}, 37 \pm 9.68 \mathrm{~dB}$ and $31.80 \pm 12.40$ $\mathrm{dB}$, respectively. No significant difference was found amongst the three groups regarding pre-operative and post-operative ABG ( $p=0.85$ and $p=0.4)$, respectively. Mean $\pm S D$, wound healing time in groups $A, B$ and $C$ were $1.00 \pm 0.00,1.80 \pm 0.40$ and1.76 \pm 0.43 respectively with $p=0.0001$ and similarly postoperative pain with $p=$ 0.001 . The wound healingtime and post-operative was statistically better $(p<0.05)$ in group A (Transmeatal approach) than other groups (Table-II).

Table-I: Demographics of patients $(n=75)$.

\begin{tabular}{l|c|c|c}
\hline \multirow{2}{*}{ Gender } & \multicolumn{2}{|c|}{ Male } & n (\%) \\
\cline { 2 - 4 } & \multicolumn{2}{|c|}{ Female } & $20(73.3)$ \\
\hline Age (years) & \multicolumn{2}{|c}{ Mean \pm SD } & $26.65 \pm 9.58$ \\
\hline \multirow{3}{*}{$\begin{array}{l}\text { Site of TM } \\
\text { Perforation }\end{array}$} & \multicolumn{2}{|c|}{ Anterio-superior Quadrant } & $11(14.7)$ \\
\cline { 2 - 4 } & \multicolumn{2}{|c|}{ Anterio-inferior Quadrant } & $45(60)$ \\
\cline { 2 - 4 } & Posterio-superior Quadrant & $5(6.7)$ \\
\cline { 2 - 4 } Age (years) & Posterio-inferior Quadrant & $14(18.7)$ \\
\hline 15 & Male & Female & $\mathbf{n}(\%)$ \\
\hline $16-25$ & 6 & 1 & $7(9.3)$ \\
\hline $26-35$ & 22 & 9 & $31(41.3)$ \\
\hline $36-45$ & 20 & 8 & $28(37.3)$ \\
\hline$>46$ & 3 & 2 & $5(6.7)$ \\
\hline Total & 55 & 20 & $75(100)$ \\
\hline
\end{tabular}

Table-II: Comparison between pre-operative and postoperative air bone gap, wound healing time and postoperative pain among groups A, B \& C (transmeatal, endaural \& postaural).

\begin{tabular}{|c|c|c|c|c|c|}
\hline & & Mean & SD & $\begin{array}{c}\text { Std. } \\
\text { Error }\end{array}$ & $\begin{array}{c}p- \\
\text { value }\end{array}$ \\
\hline \multirow{3}{*}{$\begin{array}{l}\text { Pre- } \\
\text { Operative } \\
\text { ABG }\end{array}$} & Group A & 37.60 & 11.28 & 2.25 & \multirow{3}{*}{0.85} \\
\hline & Group B & 37.00 & 9.68 & 1.93 & \\
\hline & Group C & 31.80 & 12.40 & 2.48 & \\
\hline \multirow{3}{*}{$\begin{array}{l}\text { Post- } \\
\text { Operative } \\
\text { ABG }\end{array}$} & Group A & 8.88 & 6.09 & 1.21 & \multirow{3}{*}{0.41} \\
\hline & Group B & 7.40 & 5.51 & 1.10 & \\
\hline & Group C & 8.48 & 7.28 & 1.45 & \\
\hline \multirow{3}{*}{$\begin{array}{l}\text { Wound } \\
\text { healing } \\
\text { time }\end{array}$} & Group A & 1.00 & 0.00 & 0.00 & \multirow{3}{*}{0.0001} \\
\hline & Group B & 1.80 & 0.40 & 0.08 & \\
\hline & Group C & 1.76 & 0.43 & 0.08 & \\
\hline \multirow{3}{*}{$\begin{array}{l}\text { Post- } \\
\text { operative } \\
\text { pain }\end{array}$} & Group A & 1.32 & 0.47 & 0.09 & \multirow{3}{*}{0.001} \\
\hline & Group B & 1.76 & 0.43 & 0.08 & \\
\hline & Group C & 1.76 & 0.43 & 0.08 & \\
\hline
\end{tabular}

ABG: Air Baig Gap

The maximum success rate of tympanoplasty type 1 was $97.33 \%$ in patients where post aural approach was adopted (Table-III). 
Table-III: Success rate of tympanoplastytype 1 in groups A, B and $C$ (transmeatal, endaural and postaural).

\begin{tabular}{l|c|c|c|c} 
& $\begin{array}{c}\text { Graft Taken } \\
\mathbf{n}(\mathbf{\%})\end{array}$ & $\begin{array}{c}\text { Graft Not } \\
\text { taken, } \mathbf{n}(\mathbf{\%})\end{array}$ & $\begin{array}{c}\text { Success } \\
\text { Rate }\end{array}$ & $\begin{array}{c}\boldsymbol{p} \text { - } \\
\text { value }\end{array}$ \\
\hline Group A & $72(96)$ & $3(4)$ & $96 \%$ & \\
Group A & $70(93.33)$ & $5(6.66)$ & $93.33 \%$ & \multirow{2}{*}{0.653} \\
\hline Group A & $73(97.33)$ & $2(2.66)$ & $97.33 \%$ & \\
\hline
\end{tabular}

\section{DISCUSSION}

Total patients studied in this study were 75 , who were divided into equal groups to look for surgical outcomes of all three approaches to middle ear. This study is of unique nature, as in this study, all three approaches have been studied, which is contrary to other studies where only two approaches have been studied. Although in this study male were dominant with $73 \%$, that is contrary to study of Sharma where females were common (61\%). ${ }^{6}$ However majority of studies showed male predominance, probably due to easy reach of men to seek healthcare. We observed that the most of cases presented in second and third decades $31(41.33 \%)$ and $28(37.33 \%)$ respectively, which is in consistence with the study of Sharma where maximum cases found in $2^{\text {nd }}$ and $3^{\text {rd }}$ decades 44 (48.89\%) and $26(28.89 \%)$, respectively. Similarly, Alam's study where patients presented in $2^{\text {nd }}$ and $3^{\text {rd }}$ decades of life were $61.33 \%$ and $22.67 \%$ respectively.6.7 The reason for this may be that $2^{\text {nd }}$ and $3^{\text {rd }}$ decades is the most active stage of life, and any person in this age is more cautious regarding his health issue and gets early access to treating physician. Myringoplasty is performed for the reconstruction of TM perforation. In this study, anterio-inferior quadrant perforation was the commonest finding $44(60 \%)$, while posterio-superior quadrant perforation was the least $5(6 \%)$, that is contradictory to the study of Singh, where posterio-inferior compartment was commonly involved 11 (36.7\%). 8 Pars tensa irrespective of superior or inferior component is the area of TM membrane, which is commonly involved in TM perforation because it is directly affected by pressure changes both internallythrough eustachian tube and externally through external auditory canal. Mean pre-operative ABG in patients underwent transcanal, endaural and postaural approaches for tympanoplasty was $37.60 \pm 11.28 \mathrm{~dB}, 37 \pm 9.68 \mathrm{~dB}$ and $31.80 \pm 12.40 \mathrm{~dB}$, respectively, having no significant difference among these groups $(p>0.05)$. Khafagy et al conducted a comparative study on endoscopic and microscopic use and found that preoperative mean \pm SD ABG was $19.23 \pm 5.67 \mathrm{~dB}$ and $20.26 \pm 5.31 \mathrm{~dB}$. There was no significant difference between these two groups $(p>0.05) .{ }^{9}$ Similarly, Salam also reported thatpre- operative mean \pm SD average PTA in patients operated with microscope (group A) and those operated with an endoscope (group B) for tympanoplasty were $31.15 \pm$ $4.9 \mathrm{~dB}$ and $30.89 \pm 5.03 \mathrm{~dB}$, respectively, while pre-operative mean \pm SD $A B G$ in groups $A$ and $B$ were 18.14 $\pm 4.77 \mathrm{~dB}$ and $19.81 \pm 4.23 \mathrm{~dB}$, respectively. Thus no significant difference was found between the groups in term of PTA and ABG ( $p=0.869$ and $p=0.249) .{ }^{10}$ Jain also studied the outcome of microscopic versus endoscopic use and found that the mean \pm SD preoperative air conduction was $36.42 \pm 3.87$ and $34.33 \pm 6.37$ respectively in both groups with no statistical difference between the two groups $(p=0.18) .{ }^{11}$ We noted that mean post-operative ABG in patients underwent transcanal, endaural and postaural approaches for tympanoplasty was $8.88 \pm 6.09 \mathrm{~dB}, 7.40 \pm 5.51 \mathrm{~dB}$ and $8.48 \pm 7.28 \mathrm{~dB}$, respectively, having no statistically significant difference among these groups $(p>0.05)$. However, mean wound healing time and postoperative pain was minimum in transmeatal group $(p<0.05)$ in current study. Likely in the Khafagy study using endoscopic and microscopic approaches the mean \pm SD post-operative $\mathrm{ABG}$ was $11.67 \pm 5.31 \mathrm{~dB}$ and $13.39 \pm 7.23 \mathrm{~dB}$, respectively. Thus, there was nosignificant difference between the two groups $(p>0.05) .{ }^{9}$ Similarly, Jain also pointed out that for both microscopic and endoscopic use mean \pm SD post-operative $\mathrm{ABG}$ was $29.42 \pm 8.20 \mathrm{~dB}$ and 26.11 $\pm 5.14 \mathrm{~dB}$, with no significant difference between the microscopic and endoscopic approaches $(p=0.13) .{ }^{11}$ Salam's study finding also supports our findings as he computed that at 3 months postoperatively mean \pm SD PTA were $17.14 \pm 5.34 \mathrm{~dB}$ and $16.47 \pm 4.49 \mathrm{~dB}$ for groups $A$ and $B$. However post-operative mean \pm SD ABG were $8.47 \pm 5.04 \mathrm{~dB}$ and $8.65 \pm 3.42 \mathrm{~dB}$, and no significant difference was observed ( $p>0.05)$, and postoperatively mean $\pm \mathrm{SD}$ ABG was $8.47 \pm 5.04 \mathrm{~dB}$ and $8.65 \pm 3.42 \mathrm{~dB}$, respectively, for both groups with no significant difference $(p=0.89)$ between the two groups. 10 The success rate for transcanal, endaural and postaural approach in this study was 96\%, 93.33\% and $97.33 \%$, respectively. There was nosignificant difference between the three approaches $(p>0.05)$. Khafagy found thatoverall success rate of the microscopic and endoscopic approaches was $73.3 \%$ and $80 \%$, respectively, and there was insignificant difference between the two approaches $(p>0.05) .{ }^{9}$ Chidlow conducted a study onpractice patterns in myringoplasty surgery among Australian surgeons and found that overall success rate varied from $70-90 \% .{ }^{12}$ The success rate in the Sharma study for permeatal, endaural and postaural approaches was $73.33 \%, 83.33 \%$, and $86.66 \%$, respe- 
ctively. However, statistical analysis showed no significant difference in the success rate between the three approaches $(p>0.10){ }^{6}$

It is revealed from literature that the success rate of surgical intervention for TM reconstruction is not merely associated with the approaches, rather diameter and location of ear drum rupture, external auditory canal width and surgeon preference also play important role. ${ }^{13-18}$

\section{ACKNOWLEDGMENT}

We acknowledge the work of Syed Hamid Statesian in helping statistical analysis of my data.

\section{LIMITATION OF STUDY}

Limitation of this study is a small sample size with shorter follow-up, so other studies with large sample size and long follow up may be recommended to look for longterm results.

\section{CONCLUSION}

Tympanoplasty type 1 is the ideal surgical procedure performed for closure of the tympanic membrane perforation and dealing with middle ear pathology. The choice of any of the three approaches depends on the diameter and site of the ear drum perforation, external auditory canal width and surgeon preference. Although wound healing time and postoperative pain were significantly minimum in transmeatal approach for tympanoplasty, but overall success rate of tympanoplasty was not statistically significant among these three approaches.

\section{Conflict of Interest: None.}

\section{Authors' Contribution}

FW: Conception of work, wrting of introduction, AM: Literature Review, MS: Critical revision, BZ: Data Collection, HUR: Data Analysis, NUH: Writing of discussion, MJ: Writing of results

\section{REFERENCES}

1. Umamaheswaran P, Mohanty S, Manimaran V, Jayagandhi S, Jeyabalakrishnan SP. A comparative study of sequential vs. simultaneous type I tympanoplasty in patients with bilateral chronic otitis media-Mucosal type. J Otol 2020; 15(1): 59-61.

2. Huang TY, Ho KY, Wang LF, Chien CY. A Comparative study of endoscopic and microscopic approach type 1 tympanoplasty for simple chronic otitis media. J Int Adv Otol 2016; 12(1): 28-31.

3. Patel J, Aiyer RG, Gajjar Y, Gupta R, Raval J, Suthar PP. Endoscopic tympanoplasty vs microscopic tympanoplasty in tubotympanic csom: a comparative study of 44 cases. Int J Res Med Sci 2015; 3(8): 1953-1957.
4. Shakya D, Arun KC, Nepal A. A comparative study of endoscopic versus microscopic cartilage type I tympanoplasty. Int Arch Otorhinolaryngol 2020; 24(1): 80-85.

5. Ramalingam V, Kamindan K, Murugan RK, Rajeswari V. A comparative study on outcome of Type I Tympanoplasty using sliced 1-mm Conchal cartilage and full-thickness Conchal cartilage for grafting. Egypt J Otolaryngol 2020; 36(2): 5-8.

6. Sharma DK, Singh S, Sohal BS, Singh B. Prospective study of myringoplasty using different approaches. Ind J Otolaryngol Head Neck Surg 2009; 61(2): 297-300.

7. Alam KMN, Alam MM, Hossain MD, Karim MA, Hossain MA, Sarker MZ. Comparative study of different approaches of myringoplasty in chronic otitis media. Bang J Otorhinolaryngol 2016; 22(1): 21-25.

8. Singh MN, Hamam PD, Lyngdoh NC, Priyokumar OS. Evaluation of hearing status in pre and postoperative endoscopic type 1 tympanoplasty and its infl uencing factors. J Med Soc 2014; 28(2): 166-170.

9. Khafagy MSE, El-Habashy HSE, El-Hamshary MTME. Comparative study between endoscopic and microscopic tympanoplasty through transcanal approach. Al-Azhar Med J 2020; 49(1): 83-90.

10. Salam RTA, Nambiar SS, Anusha V. Comparative study of the outcomes of tympanoplasty by the conventional microscopic and endoscopic techniques. Int J Sci Stud 2018; 6(9): 81-86.

11. Jain S, Kumar D, Singh SP, Upadhyay VP, Dubey AK, Singh HN. Comparative study of advantages and disadvantages of endoscopic versus conventional myringoplasty - a prospective study. Int J Otorhinolaryngol Clin 2018; 10(3): 81-86.

12. Chidlow C, Prunty S, Hinton-Bayre A, Shubhraj S, Renton J, Kuthubutheen J. Practice patterns in myringoplasty surgery among Australian surgeons. Aust J Otolaryngol 2020; 3(2): 28-32.

13. Lee SY, Lee DY, Seo Y, Kim YH. Can endoscopic tympanoplasty be a good alternative to microscopic tympanoplasty? a systematic review and meta-analysis. Clin Exper Otorhinolaryngol 2019; 12(2): 145-155.

14. Aggarwal P, Sohal BS, Goyal JP. Comparative study of endoscopic tympanoplasty and conventional tympanoplasty. Int J Otorhinolaryngol Head Neck Surg 2020; 6(2): 1804-1810.

15. Aggarwal SK, Dev R. Comparative study of tympanoplasty and its outcome in various age groups using the middle ear risk index scale. Ind J Otol 2020; 26(1): 4-8

16. Ojha T, Kansara A, Yogi V. Comparative study of cartilage shield tympanoplasty vs temporalis fascia graft tympanoplasty: a retrospective study. J Mahatma Gandhi Univ Med Sci Tech 2019; 4(3): 71-73.

17. Awan Z, Bashir H, Hussain A. Myringoplasty: A comparative studyof different graft materials andvarious surgical techniques. Ann Pak Inst Med Sci 2008; 4(4): 209-211.

18. Sridhara Narayanan D, Vijay Kumar B, Hari PM. Comparative study of graft materials used in myringoplasty. J Pharm Sci Res 2016; 8(12): 1339-1342. 